\title{
Noir / Noire: \\ recepción y transformación del cine criminal en la literatura y el cine argentinos
}

\author{
Román Setton
}

Recibido: 30.10.2020 — Aceptado: 20.11.2020

\section{Titre / Title/ Titolo}

Noir / Noire: réception et transformation du cinéma criminel dans la littérature et le cinéma argentins

Noir / Noire: Reception and Transformation of Crime Film in Argentine Literature and Cinema

Noir / Noire: ricezione e trasformazione del film criminale nella letteratura e nel cinema argentini

\section{Resumen / Résumé / Abstract / Riassunto}

Desde la consolidación de los procedimientos del MRI (Modo de Representación Institucional), el vínculo entre literatura y cine dejó de ser unidireccional -esto es, desde la literatura hacia el cine-. En ese sentido, el desarrollo del género negro o policial o criminal se presenta como un campo de análisis por demás significativo, si atendemos de manera simultánea a su evolución en el cine y la literatura. En Argentina, a diferencia de lo que sucedió en Estados Unidos y Francia, el desarrollo del cine criminal fue contemporáneo al policial negro literario. En este trabajo, nos proponemos mostrar que existe en Argentina una literatura policial negra temprana, en contraste con la historia clásica del género en el país. Esta literatura se desarrolló, en gran medida, a partir de la recepción y transformación del cine criminal estadounidense.

Depuis la consolidation des procédures du Mode de Représentation Institutionnel (MRI) du cinéma, le lien entre littérature et cinéma a cessé d'être unidirectionnel, c'est-à-dire de la littérature au cinéma. En ce sens, le développement de la fiction criminelle semble être un champ d'analyse extrêmement important, si l'on observe à son évolution dans le cinéma et la littérature. En Argentine, contrairement à ce qui s'est passé aux États-Unis et en France, le développement du film criminel était contemporain de la tradition littéraire du roman noir. Dans cet article, je montre un développement précoce de la littérature noire, contrairement à l'histoire classique du genre en Argentine. Cette littérature est née, dans une large mesure, de la réception et de la transformation du cinéma criminel américain.

Since the consolidation of the IMR (Institutional Mode of Representation), the link between literature and cinema ceased to be unidirectional, that is, from literature to cinema. The development of crime fiction appears to be a relevant field of analysis, if we simultaneously attend to its evolution in both film and literature. In Argentina, unlike what happened in the United States and France, the development of crime film went parallel to the development of the hard-boiled literary tradition. In the article I show an early development of hard-boiled literature in Argentina, in contrast to the classic history of the genre in the country. This literary field developed, to a large extent, thanks to the reception and transformation of the American crime cinema.

Con il consolidamento delle procedure del MRI (Modo di Rappresentazione Istituzionale), il rapporto tra letteratura e cinema ha cessato di essere unidirezionale, vale a dire, dalla letteratura al cinema unicamente. In questo senso, lo sviluppo della narrativa criminale è un campo di analisi estremamente significativo, se prestiamo attenzione simultaneamente alla sua evoluzione tanto nel cinema quanto nella letteratura. In Argentina, a differenza di quanto accaduto negli Stati Uniti e in Francia, lo sviluppo del film criminale è stato contemporaneo al genere hard boiled. In questo articolo mi propongo di mostrare uno sviluppo precoce del genere hard boiled in Argentina, in contrasto con la storia classica del genere poliziesco. Tale letteratura si è sviluppata, in larga misura, grazie alla ricezione e alla trasformazione del cinema criminale americano. 


\section{Palabras clave / Mots-clé I Key words /Parole chiave}

Cine de gangsters, Roberto Arlt, Jorge Luis Borges, Luis Saslavsky, literatura policial argentina.

Film de gangsters, Roberto Arlt, Jorge Luis Borges, Luis Saslavsky, littérature criminelle argentine.

Gangster films, Roberto Arlt, Jorge Luis Borges, Luis Saslavsky, Argentine crime literature.

Films di gangsters, Roberto Arlt, Jorge Luis Borges, Luis Saslavsky, letteratura criminale argentina.

\section{Introducción}

Los estudios de la literatura policial argentina suelen situar los comienzos del género hacia 1940, con los relatos de Jorge Luis Borges, Adolfo Bioy Casares, el Padre Castellani, Manuel Peyrou, Silvina Ocampo, etc. ${ }^{1}$ Como puede advertirse, esta historiografía vincula los orígenes, por cierto esplendorosos, a miembros muy visibles del grupo de la revista Sur, y enmarca estos cuentos y novelas dentro del relato clásico de enigma en lengua inglesa.

El comienzo de la vertiente negra de la literatura policial, en cambio, ha sido visto como un largo desarrollo desde comienzos de la década de 1960 -y con un antecedente en las producciones de David Viñas de 1953, escritas bajo el seudónimo de Pedro Pago-, a partir de las numerosas contribuciones de Eduardo Goligorsky -como autor, director de colección, traductor-y los textos teóricos sobre el género de Juan José Sebreli, hasta llegar en 1969 a la colección Serie Negra,

cf. Walsh; Yates, 1960; Bajarlía, 1964 y 1990; Fèvre, 1974; Braceras/Leytour, 1993; Lafforgue/Rivera, 1977 y 1996; Lagmanovich, 2007; solamente por nombrar algunos. Otra corriente, más reciente y mucho menos caudalosa, retrotrae ese inicio hacia el último tercio del siglo XIX, con las primeras novelas de Raúl Waleis y los relatos breves de Paul Groussac, Carlos Olivera, Carlos Monsalve, y con las novelas cortas de Eduardo L. Holmberg (Barcia, 1988/1989; Ponce, 1997 y 2001; Setton, 2012 y 2015; Pérez, 2015; Vilariño, 2019; Lemo, 2019). dirigida por Ricardo Piglia, y la compilación Misterio 5, que por primera vez ofrece una antología del género negro. ${ }^{2}$ Dentro de este marco, Piglia señaló el año de 1960 como el punto temporal que marca una «escisión que enfrentaba, también aquí, a la policial de enigma con la violencia social de la serie negra» (1993, 8). Así se configura un desarrollo esquemático y orgánico del género: la literatura de enigma desde 1940, con algunos antecedentes significativos en la década de $1930,{ }^{3}$ que se desarrolla y extiende con vigor hasta fines de la década de 1950, y la literatura policial negra, que empieza a desarrollarse hacia 1960 y llega a su cumbre hacia 1970.

Sin embargo, cabe presentar algunas objeciones a esta construcción: 1) la literatura policial de las décadas de 1930 y 1940 no sólo se alimentó de la tradición clásica inglesa, también abrevó en las películas de gangsters, el film noir, el police procedural y las transposiciones de estos géneros que se dieron en el cine nacional -todo aquello que podríamos comprender como el cine criminal argentino-; 2) los comienzos de la serie negra pueden ser situados mucho antes de lo que lo hace la historia instalada del género en el país; en consecuencia, 3) la escisión entre novela clásica y negra ya podía ser percibida -y lo fue- mucho antes de lo señalado por Piglia; 4) de este modo, el cine y la literatura negras se desarrollan en Argentina de manera casi simultánea, a diferencia de lo que se puede observar en el ámbito de habla inglesa.

\section{Arlt y Borges en la década de 1930}

Nadie puede negar que en los treinta y, más aún, en los cuarenta, se desarrolla en Argentina una vigorosa narrativa policial que sigue el modelo del policial inglés de la Edad de Oro, e incluso no es difícil hallar representantes del armchair detective, cuyo primer representante es Mycroft, el hermano de Sherlock Holmes. Sin embargo, también encontramos otra vertiente con características

cf. Lafforgue y Rivera (1987, 1996); Giardinelli (1996); Mattalia (2008); De Rosso (2012)

cf. Yates, 1960; Lafforgue / Rivera, 1996. 


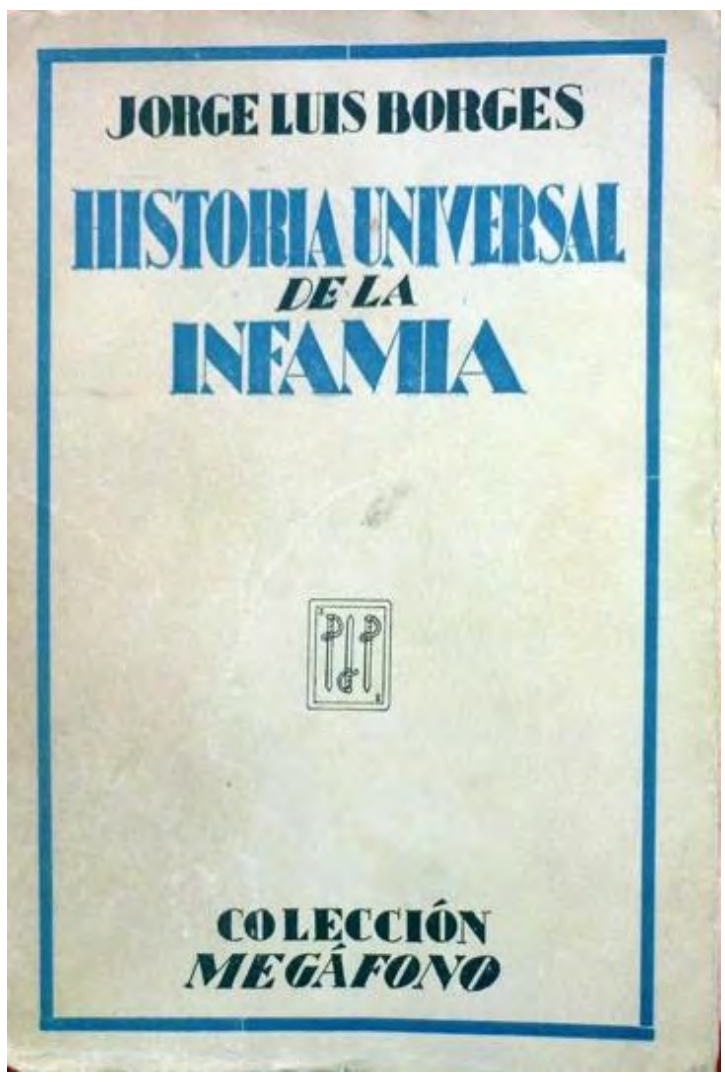

afines a la serie negra: la del Roberto Arlt de «Un argentino entre gangsters» (1937) y «Las fieras» (1933), el Borges de Historia universal de la infamia (1935), el Luis Saslavsky de $A$ sangre fría (1947). Estas dos formas representan tipos de criminales e investigadores diferentes: la primera ofrece detectives y criminales que podríamos caracterizar como artistas (sofisticados, exquisitos, coleccionistas, aristocráticos, con gustos intelectuales e improductivos como forma de distinción); la segunda se ocupa del gangster, el asesino serial, o impulsivo, o a sueldo, los hombres y las mujeres fatales; y el detective, si lo hay, es un sujeto quebrado y con relaciones al menos ambiguas con la ley. De la propia descripción se puede colegir que esta última tuvo un diálogo mucho más frecuente y productivo con el cine. ${ }^{4}$

\footnotetext{
El policial de enigma encontró su género cinematográfico, al menos parcialmente, en el police procedural y en las transposiciones de las novelas famosas, por ejemplo Asesinato en el Orient Express (Murder on the Orient Express, 1974), dirigida por Sidney Lumet. En los últimos tiempos, muchos de los detectives clásicos de las novelas de enigma han sido llevados a la pantalla, ya sea en formato película o serie.
}

La irrupción de las proyecciones de crimen visuales y audiovisuales (a partir de la incorporación del sonido) fue transformando, paulatinamente, el imaginario sobre «lo policial» y el crimen en la ciudad. En la literatura de Arlt esto puede observarse con claridad, pues las fantasías cinematográficas afectan de manera directa la exposición de los personajes. Los pensamientos de Erdosain, por ejemplo, son por momentos «como en los desenvolvimientos de las películas norteamericanas, donde el pordiosero de ayer es el jefe de una sociedad secreta de hoy, y la dactilógrafa aventurera una multimillonaria de incógnito» $(1997,164)$. Desde sus comienzos, con The Great Train Robbery (Edwin S. Porter, 1903), pasando por algunos de los primeros filmes de Josef von Sternberg Underworld (1927), The Docks of New York (1928) - y luego con las biografías de grandes delincuentes como Public Enemy (William A. Wellman, 1931), Little Caesar (Mervyn LeRoy, 1931), Scarface (Howard Hawks, 1932) o historias de convictos inocentes como I am a Fugitive from a Chain Gang (Mervyn LeRoy, 1932), el cine dio un lugar privilegiado a las tramas de carácter policial. Así, importantes modelos narrativos y comunicacionales fueron recibidos y transformados en la literatura (policial), además de que fueron un importante influjo para el desarrollo de los diversos cines nacionales. En la Argentina, ya algunas películas tempranas como La cbica de la calle Florida (1922) o Perdón, viejita (1927), ambas dirigidas por José Agustín Ferreyra, incorporaron tramas de tipo policial y dividieron el ámbito de la ciudad -el barrio, el centro, el parque suburbano, el café del centro- según una perspectiva moral y legal..$^{5}$ Más adelante, con la llegada del sonido, «lo policial» fue teniendo cada vez más peso en los argumentos de los filmes, tal como se puede ver en películas como Monte criollo (Arturo S. Mom, 1935), Melodías porteñas (Luis José Moglia Barth, 1937), Palermo (Arturo S. Mom, 1937), La fuga (Luis Saslavsky, 1937), La vuelta de Rocha (Manuel Romero, 1937) y muchas otras. Así, al menos a partir de la década de 1920, la literatura desarrolló un intenso diálogo con el cine, tanto nacional como extranjero.

Cf. Tranchini, 1999, Gil Mariño, 2012, Setton, 2017. 
En su retrato del ámbito urbano, las aguafuertes de Arlt muestran el delito con rasgos que provienen del imaginario cinematográfico. Como un condimento excitante de la vida, el delito adquiere una gran productividad narrativa.

Pero basta entrar a esta calle [Corrientes] para sentir que la vida es otra y más fuerte y más animada. Todo ofrece placer. [...] Y libros, mujeres, bombones y cocaína, y cigarrillos verdosos, y asesinos incógnitos, todos confraternizan en la estilización que modula una luz supereléctrica. (Arlt, 1998, 231; las cursivas son mías).

Se trata de nuevas, modernas representaciones del crimen y el criminal, mediadas por el cine y las nuevas tecnologías. A diferencia de lo que sucedía en los policiales del siglo XIX y comienzos del XX -las narraciones de Luis V. Varela, Paul Groussac, Eduardo Holmberg, Félix Alberto de Zabalía o Vicente Rossi-, el criminal ya no es aquí el individuo que pervierte la sociedad y al que hay que reformar, expulsar o exterminar-según el caso-, sino, por el contrario, un integrante más de esta sociedad. Más aún: se ha vuelto admirable, al menos en parte, y ha adquirido sus propios derechos:

El hurto es una cosa vulgar e indigna. En cambio el robo es casi una especie de adquisición de derechos. El hurto quedó para los amigos de lo ajeno, taimados y cobardes. Para aquellos que se metían de noche en una casa y sin despertar a nadie, andando de puntillas [...] Para los que de noche, de noche siempre, saltando cercos y tapias, se metían en cercados ajenos y a quien desafiaban a lo sumo era a algún perro guardián [...] Eso es el hurto: posesionarse ocultamente de lo ajeno. Repugna y es cobarde.

En cambio, el robo hasta tiene cierta elegancia. Sacarle en sus propias narices a un señor todo lo que es suyo no es cosa de patanes. Hay que tener escuela, y hacerlo en forma audaz; en plena calle Florida y Corrientes, por ejemplo, a las 18:30 horas, es un acto que casi da derechos legales de posesión sobre las cosas robadas. Porque si a la víctima le sacan el fruto de varios años de trabajo y peligros, el salteador en un solo momento expone también su vida y hasta su reputación. («El asalto», 1922, 5-7)

En el marco de estos discursos contemporáneos, la literatura de Roberto Arlt -quien también ejerció la

Citamos el texto por el título ya que se trata de un texto anónimo. crónica policial (y cinematográfica) - gira y se arma en torno a «lo policial»: el robo, el asesinato, la delación, el proxenetismo, la asociación ilícita, el delito político en diferentes modalidades (la conspiración, el complot, la revolución, el atentado, etcétera) proliferan en su narrativa. Al menos desde 1927 Arlt escribió una serie de relatos policiales según el modelo del policial de enigma: «Un error judicial» (1927), «El hombre del turbante verde» (1939), «Jabulgot el farsante» (1940). En paralelo, escribió una serie de relatos que se acercan al modelo duro o hard-boiled del policial, entre ellos «Las fieras», «La pista de los dientes de oro», «Un argentino entre gangsters», «La venganza del mono» $\mathrm{y}$ «El misterio de los tres sobretodos». ${ }^{7}$ Todos ellos revelan además un importante influjo de la ficción cinematográfica. ${ }^{8}$ Por una cuestión de espacio, nos ocuparemos aquí sólo de «Un argentino entre gangsters» (1937).

El breve relato narra el secuestro y extorsión del ingeniero argentino Humberto Lacava por la banda de Tony Berman. El propósito de estos criminales es forzarlo a construir una ruleta con trampa, de manera tal que el crupier pueda elegir en cada jugada qué número será el ganador. Por este ‘trabajo', al ingeniero le ofrecen veinte mil dólares y su vida, i. e. no matarlo. Los criminales le proporcionan todos los instrumentos necesarios y Lacava durante largos días diseña y va perfeccionando la ruleta. Sin embargo, comprende con rapidez que habrán de matarlo una vez acabada la tarea. Por ello demora la 'finalización' del trabajo. Lacava va ajustando uno a uno los números de la ruleta y aguarda con paciencia el momento oportuno hasta que: «Tony, Frank y Eddie se inclinaron sobre el disco que debía detenerse frente al número 36. Lacava sintió que una ola de sangre le abrasaba las mejillas: [...] Eddie, con sus enormes manos de chocolate, apretaba sobre las bisagras del canto de la mesa, igual que Tony y Frank. »

\footnotetext{
El protagonista de «La venganza del mono» es un asesino a sueldo como los que ya había representado el cine.

8 Otros cuentos, «La doble trampa mortal» (1937), «La cadena del ancla» (1938) $\mathrm{y}$ «Espionaje» (1938), remiten al cine, en este caso de espionaje, tal como ya lo encontramos en la época silente (O.H.M.S., 1913, Alexander Butler; El peligro del espía alemán, 1914, Bert Haldane) y luego en importantes películas de Fritz Lang (Dr. Mabuse, el jugador, 1922, Espias, 1928, El testamento del Dr. Mabuse, 1933, ) o Alfred Hitchcock (El hombre que sabia demasiado, 1934; Los 39 escalones, 1935; Sabotage 1936).
} 
(Arlt, 1994, 32-33) Lacava presiona un botón y los tres gangsters mueren electrocutados.

Muchos elementos presentes en el cuento permiten inscribirlo dentro de la serie negra: el hecho de que se trata de un mundo ambiguo en que la división moral entre el bien y el mal no es precisa, la perspectiva por completo interior a ese mundo, sin un punto de vista exterior que encarne la perspectiva de la ley o del bien, la importancia decisiva del dinero como motor central de las acciones y como centro de la trama (Piglia, 2000). En estas ficciones, como afirma Sebreli, «no se trata de buscar quién fue el asesino, no interesa saber quién apretó el gatillo», «en el mundo del mal es imposible la constitución de ningún tipo de sociedad, al no haber reivindicación alguna en común» (229), «cuando alguien confía en otro [...] seguramente se perderá» (229-230). Según esta caracterización del género negro, todas las relaciones son contingentes y están amenazadas por la desconfianza y la traición (232). Este fenómeno no es ajeno a la contratación del héroe. No son pocas las novelas de Hammett y Chandler en que el cliente que contrata al héroe o el amigo que lo lleva a involucrarse en el conflicto lo amenazan de muerte o lo engañan o le tienden una trampa que pone en peligro su vida (cf. El halcón maltés, Cosecha roja, Adiós, muñeca, El largo adiós, etcétera). De manera análoga a lo que sucede en Cosecha roja, Humberto Lacava elimina a todos los gangsters y restablece el orden. Estas coincidencias no nos deberían hacer olvidar la importancia del cine en ese entonces.

Lila Caimari (2004) señaló que durante la década de 1930 el impacto del cine era tan fuerte que en muchas oportunidades las crónicas de los diarios en los años veinte y treinta trataban de asimilar los sucesos acaecidos en Buenos Aires con episodios de gangsters y ametralladoras, tal como los espectadores los podían ver en el cine.

1930 es empírica y simbólicamente un año de quiebre en el mundo y en la representación del crimen. En Estados Unidos, la gran depresión, el crack bursátil, la Ley de Prohibición, contribuyeron de manera determinante

Según la tesis de Piglia (Crítica y ficción), en la serie negra, el dinero es siempre el móvil, la causa eficiente y final de las acciones. con los cambios en la representación del crimen; y a partir del cine se fue construyendo y difundiendo en gran parte del mundo la figura del gangster como enemigo público (Warshow, 1964). En la Argentina, esta recepción se potenció por la popularidad que cobraron entonces algunos bandidos locales -Chicho Chico, Chicho Grande, Mate Cosido- y por cambios vinculados con las agencias de noticias -que dirigieron su atención, cada vez más, a las noticias estadounidenses (Caimari, 2012) -, la prensa gráfica -la presencia creciente del mundo del cine- y los cambios estructurales en el paisaje urbano, que reconfiguraron diferentes zonas de la ciudad (Gorelik, 1998). Por estos motivos, va perdiendo importancia en la prensa, en la literatura y en el cine un modelo de delito que podemos calificar como nocturno, en muchos casos rural y fundamentalmente vinculado con la vida doméstica. Esto trae aparejado, un desplazamiento en la representación del crimen y del criminal: el gangster, que se mueve en automóvil y utiliza el arma a repetición -la ametralladora-, pasa a ocupar el centro de la escena y queda desplazado el cuchillero de los arrabales, que poblaba el discurso de la prensa (a comienzos de siglo) y (una década después) el tango y la literatura.

Patricio Fontana ha analizado con detalle las aguafuertes de Arlt vinculadas con el cine. En «El cine y los cesantes», frente al derrumbe económico mundial y local, Arlt encomia al cine como refugio de los desocupados, al que pueden acceder «por un módico precio» (101); en «Calamidades del cine», en cambio, censura a los padres que concurren a las salas con bebes (102) e impiden el disfrute silencioso del filme. Las películas de gangsters que invadieron las pantallas en la década de 1930 llegaron, como es natural, a la Argentina: «Los porteños también ven los futuros clásicos del género: El enemigo público, $P e$ queño César, Scarface. Todos los representantes del subgénero pistolero, relevantes e irrelevantes, son proyectados en los flamantes cines de Buenos Aires a poco de su estreno en Estados Unidos» (Caimari, 2012, 182). Roberto Arlt, «enteramente obsesionado por el mundo del delito, la tecnología y las utopías de enriquecimiento vertiginoso», «no es inmune a los encantos de los gangsters de película. A fines de los treinta, sus reseñas del delito 


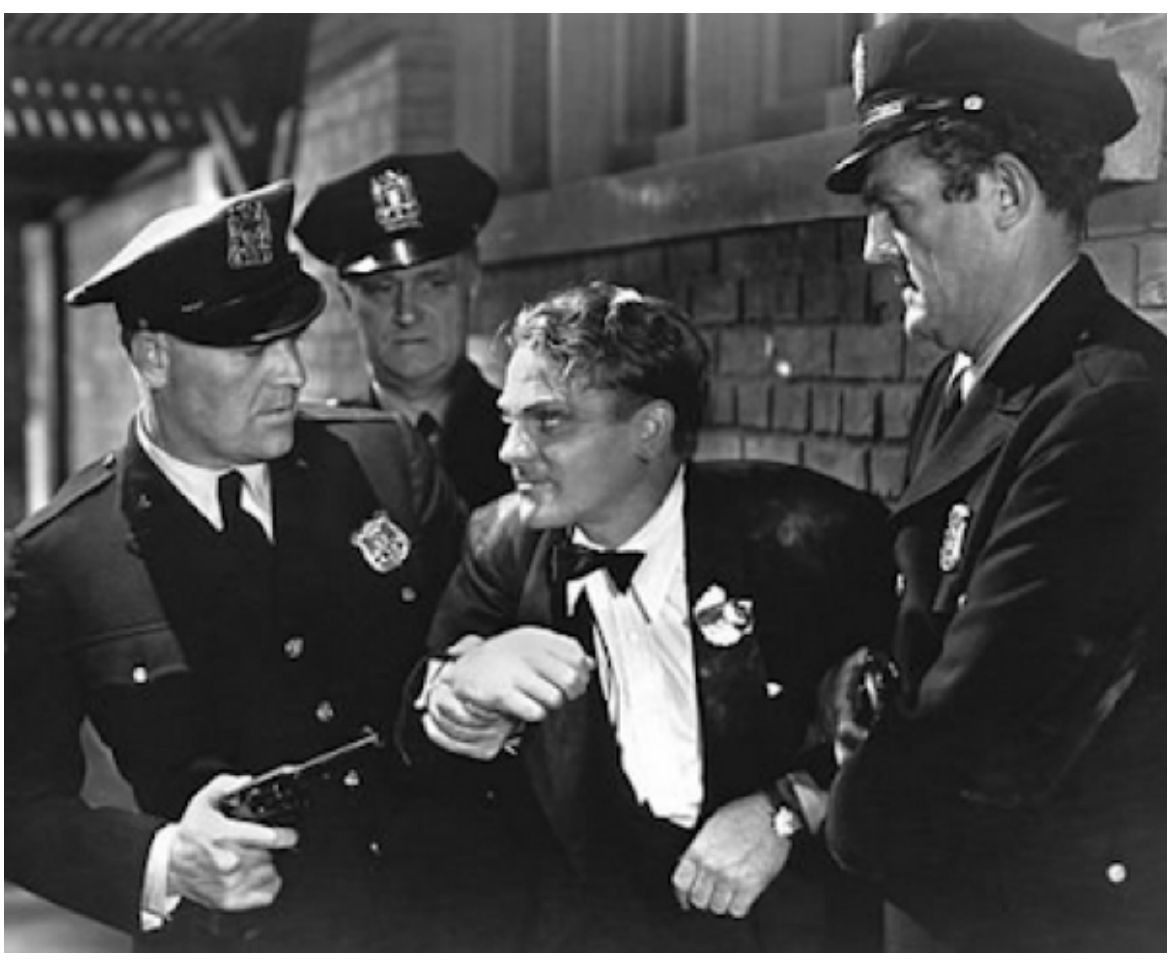

El enemigo público (The Public Enemy, William A. Wellman, 1931)
(Borges, I, 289). Como indican con precisión Gonzalo Aguilar y Emiliano Jelicié, en ese libro, la acción propia de los folletines y las novelas de aventuras tiene una significación que se irá reduciendo, de manera paulatina, con el avance de los años y los libros: «todavía Historia universal de la infamia abunda en «riesgos físicos» y «aventuras corporales», y está más próxima al filme de malhechores y gangsters que los relatos de Ficciones, que exponen problemas ficcionales más cercanos al enigma del policial inglés» (17). En sintonía con esta idea, Aguilar y Jelicié ven en Historia universal de la infamia personajes que no están integrados en ninguna colectividad, pero que son capaces del coraje (18). En efecto, muchos de los protagonistas de las historias pueden ser descritos de ese modo (La viuda Ching, Monk Eastman, Billy estadounidense están salpicadas de palabras en inglés y personajes del hampa que usan ametralladoras, corbatas de seda, fuman cigarros y se llaman Tony Berman o Frank Lombardo» (Caimari, 182). Como es previsible, elementos de las crónicas pueden encontrarse también en las ficciones literarias. La frase inicial de «Un argentino entre gangsters» es un claro ejemplo: «Tony Berman descargó la ceniza de su cigarro sobre el piso encerado» (23).

También la temprana narrativa de Borges recibe una gran influencia del cine. Esto se muestra con claridad en Borges y el cine, de Edgardo Cozarinsky: «El cine (más bien una idea del cine) aparece asociado en Borges a la práctica de la narración, aun a la posibilidad misma de abordar la narración» (10). El propio Borges ha reconocido, de hecho, la significación del cine en sus comienzos como narrador. En el prólogo a Historia universal de la infamia afirma: «Los ejercicios de prosa narrativa que integran este libro fueron ejecutados de 1933 a 1934. Derivan, creo, de mis relecturas de Stevenson y de Chesterton y aun de los primeros filmes de von Sternberg» the Kid, el narrador anónimo de «Hombre de la esquina rosada»); otros practican sencillamente la abyección, la crueldad y la canallada (Lazarus Morell), o simplemente la ingratitud (el deán de «El brujo postergado»), el fraude o la estupidez (Tom Castro ${ }^{10}$ y su compañero Bogle).

Más allá de las aventuras físicas y del coraje de la lucha corporal o armada, el libro ofrece una galería de personajes infames que no es ajena a la narración cinematográfica. También Borges se nutre del imaginario gangsteril generado y difundido por el cine. Esto se observa, por ejemplo, en «El proveedor de iniquidades Monk Eastman». Sin embargo, en este relato la condición de gangster de Eastman importa menos que su condición de guapo y compadrito. (De modo similar, la condición de gangster de Red Scharlach en «La muerte y la brújula» importa menos que su identificación con el detective Erik Lönnrot). De hecho, el desprecio de Borges por el gangster, por su carácter de hombres de

Cf.: «persona de una sosegada idiotez» (Borges, I, 301). 
negocios, se verifica en «El atroz redentor Lazarus Morell»: «Al Capone y Bugs Moran operan con ilustres capitales y con ametralladoras serviles en una gran ciudad, pero su negocio es vulgar. Se disputan un monopolio, eso es todo» (Borges, I, 297-298). Robert Warshow ha remarcado la similitud del gangster cinematográfico con el hombre de negocios, al destacar su imposibilidad de establecer vínculos afectivos, su soledad inevitable y trágica, su consideración de los seres humanos como medios. El camino del gangster, nos dice, es ascender, ascender y ascender, ese es su único lema y en eso radica su éxito. «The World is Yours», reza el cartel luminoso que vemos desde el departamento de Scarface. Pero no hay un lugar al que llegar. Toda la vida del gangster es trabajo y finalmente muere asesinado, porque es un mundo en que las únicas relaciones posibles son las de dominación y sumisión. El sueño del gangster es, como afirma Warshow, infligir el máximo daño posible y dominar el mundo. La descripción de Al Capone y Bugs Moran, pero también el recorrido de Monk Eastman se aproximan con claridad al gangster cinematográfico descrito por Warshow. Así como el gangster está presente en este libro, también encontramos al cowboy, Billy the Kid. Como ha señalado Warshow, los géneros más exitosos del cine estadounidense: «Las dos creaciones más exitosas del cine norteamericano son el gangster y el cowboy: hombres con armas. Armas como objetos físicos y las actitudes asociadas con su uso conforman el centro visual y emocional de los dos tipos de films» (89).

Pero más allá de los temas, el influjo más vigoroso del cine lo podemos observar en los procedimientos. Esto explica que el texto en que cobra mayor peso la experiencia de Borges como espectador de cine sea el único de tema local de todo el volumen: «Hombre de la esquina rosada». Se trata del relato que inicia la serie de cuentos de cuchilleros y a la vez de su primer cuento en sentido estricto. Como sabemos, Borges conscientemente intentó realizar ese cuento como si fuera un pequeño filme. El cuento, nos dice, tiene un «propósito visual» (Borges, I, 289) y fue escrito voluntariamente como «una serie de imágenes» (Borges, en Charbonnier, 89), al modo «del Josef von Sternberg de Underworld, The docks of New York,
The Dragnets (Charbonnier, 89). Es decir: el nacimiento de su narrativa está ligado de manera indisociable con su experiencia como espectador de cine. En efecto, es fácil ver en este relato que toda la escena del ingreso de Francisco Real al baile y hasta su desafío a Rosendo Juárez parece escrita como una larga escena cinematográfica, en parte articulada mediante un montaje que analiza dramáticamente las acciones, en parte en una suerte de travelling o de cámara en mano. De este modo, acompañamos el avanzar del Corralero hasta Rosendo. ${ }^{11}$ La infamia de Rosendo Juárez, así como la de muchos otros de los protagonistas del libro, está vinculada de manera estrecha con ese mundo de muerte, humillación y persecución del dinero y el poder que caracteriza a la serie negra. También más adelante encontramos en Borges cuentos con temas y motivos tomados del género negro (un ejemplo muy claro es «Emma Zunz»), más allá de que en sus textos críticos y teóricos haya defendido hasta el cansancio el policial de enigma y atacado la novela dura.

\section{Luis Saslavslky}

El diálogo fluido entre el cine y la literatura criminales en Argentina explica que una de las primeras novelas nacionales de la serie negra haya sido escrita por un importantísimo director de cine de la época clásica, Luis Saslavsky. Se trata de $A$ sangre fría (1947), su primera obra literaria. Es un texto por completo ignorado por la historia del género y de la literatura también. Anterior a su emigración motivada por sus disidencias con el peronismo, se inscribe en aquel contexto cultural -el de la Argentina de la década de 1940- en que la literatura y el cine policiales llegaron a un punto cumbre (Lafforgue / Rivera, 1977, Tassara, 1992). Asimismo, coincide con una época de intensa producción cinematográfica del autor, dentro de la cual encontramos varios filmes pertenecientes al noir o sencillamente al policial, tanto en

\footnotetext{
Cabe añadir que muchos de los duelos presentes en la literatura de Borges (por ejemplo el de «El Sur»), así como las persecuciones («El jardín de senderos que se bifurcan») o las ejecuciones que cierran los relatos («El evangelio según Marcos», «El muerto», «La muerte y la brújula») entonan con esta articulación dramáticonarrativa del cine de género.
} 
sus películas argentinas como en las francesas: La fuga (1937), Camino del infierno (1946), Las ratas (1962), La Neige était sale (1952), Les Louves (1957). ${ }^{12}$

Esto explica, al menos parcialmente, que $A$ sangre fría tenga estrechas relaciones con el cine negro y policial; menos predecibles, en cambio, son la temprana y nítida conciencia de los subgéneros literarios del policial o el posicionamiento contundente frente a la hegemonía del policial de enigma promovida por Borges y compañía. En este sentido, en cuanto a la tercera objeción que hemos formulado, cabe señalar que la propia edición de $A$ sangre fría pone de manifiesto la escisión entre los dos modelos de literatura policial. El título de la novela, la ilustración de la tapa con la mano sangrante y, fundamentalmente, la solapa delantera del libro apuntan con claridad en esta dirección. Como enuncia la misma solapa,

existen, en verdad, dos tipos de novela policial [...] El primero es aquel en que se comete un robo o crimen, sin dar a conocer el autor del hecho. El lector irá desvelando paso a paso, capítulo tras capítulo, el misterio hasta que la incógnita sea resuelta un poco antes de finalizar la novela.

En el segundo tipo de novela policial, el lector no ignora quién es el ladrón o el asesino; por el contrario, participa en el planeo y en la ejecución del robo o el crimen, padece también las alternativas de la investigación, y las fatales e inesperadas consecuencias del delito.

Resumiendo, pueden definirse estos dos aspectos con dos frases: La primera, novela tipo: ¿Quién es el asesino? La segunda, novela tipo: El asesino es tal, pero ¿qué pasará? [...]

A sangre fría pertenece al segundo tipo de novela. Ha sido desarrollada con los resortes del género, pero tiene hallazgos novedosos e imprevisibles [...] pese a la simplicidad de sus medios de expresión los caracteres están descritos con un acento muy particular y a veces profundizados con sensibilidad.

A pesar de su misterio, sus incógnitas y su crimen brutal, $A$ sangre fría se desenvuelve de pronto en un clima que hace comprensibles y humaniza a los seres que la habitan.

\footnotetext{
Sus últimas cuatro obras literarias, en cambio, tienen lugar en un momento en que su producción cinematográfica se hallaba reducida de un modo muy drástico (solamente realiza dos películas en los 31 años que van desde 1964 hasta su muerte en 1995, mientras que en los 10 años que van desde 1937 hasta 1947 realiza trece películas). La obra literaria (ficcional) de Saslavsky está compuesta -hasta donde han llegado nuestras averiguaciones- por cinco libros - A sangre fría (1947), Psicoaná lisis de una prostituta (1966), Camino para tres fantasmas (1968), El desenmascarado (1983) y La fábrica lloraba de noche (1983)-, sin contar los textos publicados en diversos diarios y revistas que nunca han sido reunidos.
}

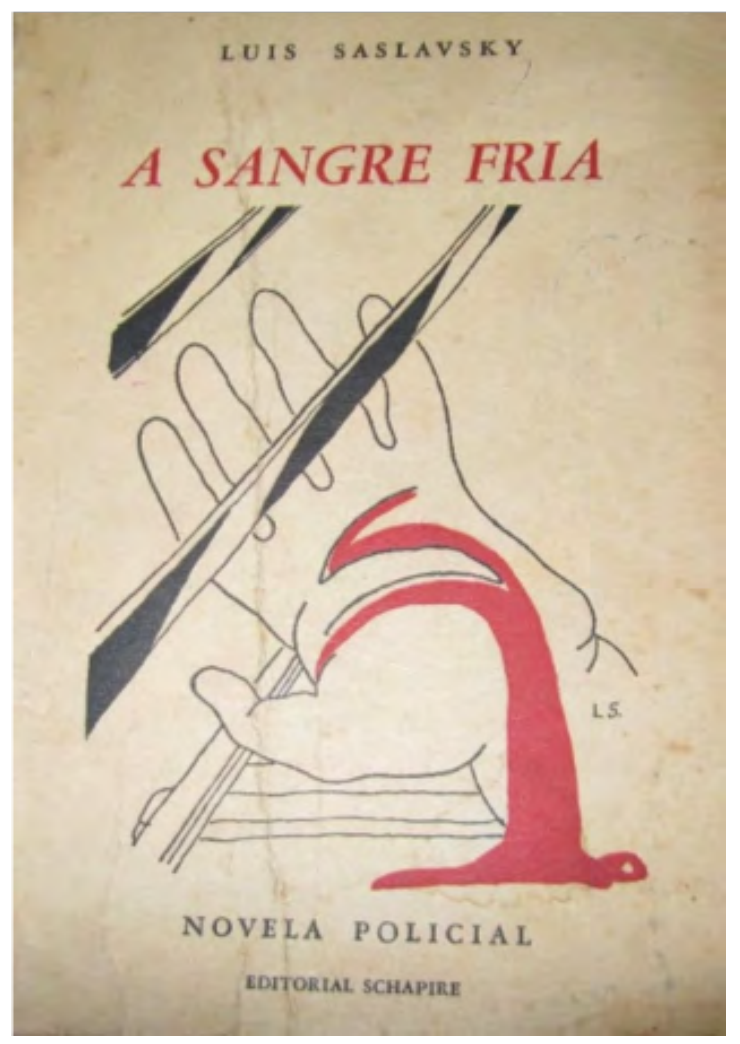

El lector no olvidará fácilmente a Elisa Dunkel, que continuará frecuentando su vida y sus recuerdos.

A diferencia de la novela de enigma o whodunit, orientada hacia el descubrimiento de los hechos pretéritos, el segundo tipo de novela, orientada hacia el futuro y cuya narración -como la del cine- está situada en un continuo presente, no es más que otra formulación de la oposición entre la novela clásica de enigma y la novela de la serie negra. En el mismo sentido se dirigen también los siguientes elementos: la insistencia en el 'clima' y los personajes - en contraste con la primacía de la trama en la novela de enigma-; la indicación del 'crimen brutal'; el apellido germano y umbrío de la protagonista -Dunkel-; el carácter humano o 'humanizado' de los seres que habitan el mundo diegético, en contraste con el esquema abstracto de personajes que supone el policial de enigma.

$\mathrm{Y}$, sin embargo, esta novela toma tanto o más del film noir que de la serie noire. A sangre fría narra el final de la vida de Elisa Dunkel, desde que sale de la cárcel -luego 
de haber cumplido cinco años de condena por colaborar con Raúl Machado en el robo de la joyería en que ella trabajaba como dependiente- hasta su muerte en el hospital, motivada por la traición de Fernando Zanni, quien la empuja desde un tren en movimiento. Estos dos caracteres masculinos, Raúl Machado y Fernando Zanni, son los personajes vinculados con la dunkle Seite [lado oscuro] de Elisa. Son a su vez los hommes fatales en su vida, que la conducen a la cárcel, en el primer caso, y a la muerte en el segundo. La alejan así de la ayuda divina inscripta etimológicamente en su nombre de pila. ${ }^{13}$ Elisa es arrastrada al crimen por un doble motivo: 1) la pasión amorosa; 2) las condiciones materiales de su origen, que le niegan toda participación en la felicidad doméstica y en la felicidad sensual propia del imaginario femenino de la época, tal como se manifestaba por ejemplo en el cine, ya sea en las producciones hollywoodenses o en las nacionales: llevar vestidos hermosos, asistir a bailes, etc.

En el primero de los crímenes, la atracción por Machado la impulsa a colaborar con el robo; pero más importante aún, en tanto motivación, es su resentimiento contra la niña Cristina (enamorada también de Machado), a quien debe servir. En una escena bisagra en su biografía, Elisa debe permanecer en la cocina, ataviada para la fiesta, con un vestido de organdí celeste y flores rosas, escuchando cómo los niños y las niñas bien disfrutan y se divierten:

Vencida se entregaba, vencida se volvía a ver como tantas veces esperando en el office o en el ante-comedor de una casa rica [...] A veces le parecía que toda su adolescencia había sido eso: esperar... Hasta el día aquel... El día del baile de Cristina, de la niña Cristina.

¿Cómo pudo ser tan tonta? ¿Por qué creyó que estaba invitada? $[\ldots]$.

En la pensión, sobre la cama, estaba extendido el vestido de baile. ¿Era un vestido de baile? De organdí celeste con flores rosadas. [...] Llegaron temprano al baile de la niña Cristina. Esta cumplía dieciocho años y la presentaban en sociedad [...] La dueña de casa las recibió emocionada y amable. [...] pasaron al office donde la señora les hizo servir la comida. Luego, durante dos horas, contemplaron maravilladas, fuentes y más fuentes,

Elisa: nombre femenino de origen hebreo que significa «La ayuda de Dios». copas de champagne, licores y helados. Del baile oía los acordes de la orquesta y un rumor incesante de risas y charlas. (22-24)

Es precisamente esta exclusión del disfrute lo que hace nacer en ella un odio hacia la sociedad toda y, fundamentalmente, a su distribución clasista e inicua del placer. La motivación del crimen es muy clara: el odio por las determinaciones sociales que la excluyen del disfrute de los placeres. «¡Ojalá se mueran! ¡Ojalá se mueran todos! Todos los que dan grandes bailes, todos los que tienen vestidos de tul con perlas bordadas» (25). Elisa quiere una vida más allá de sus determinaciones económicas de clase, y el único medio para lograrlo lo encuentra, previsiblemente, en el dinero: «iDinero! ¿me oyes bien? Dinero» (33).

Pero los incentivos para el crimen no son únicamente materiales. Su voluntad de liberarse de esa vida de privaciones esconde un sentido más profundo, psicológico, vinculado al rechazo de sí. Por eso su pregunta - ¿Cómo librarme de ser lo que soy?» (32) - implica una motivación de carácter suicida, que va a signar su destino: «iY los que se sientan en un office entre el ruido de las bandejas y los platos y han creído ser invitados, ojalá se mueran también!» (25).

Como anticipamos, muchos son los elementos en que se puede advertir una alimentación mutua entre el cine y la literatura de Saslavsky: el personaje de la cantante Moreno así como el inspector Robles (en La fuga) anticipan no solamente en sus nombres a la cantante Moreno y al inspector Robledo (en la novela $A$ sangre fría); el peso del pasado melodramático en Camino del infierno -que abre las ventanas inopinadamente y arrastra a los personajes al asesinato y la catástrofe- anticipa el rol del pasado melodramático en la novela. Asimismo, el desplazamiento en los papeles genéricos que hemos indicado en $A$ sangre fría -los hombres fatales, en lugar de las mujeres fatales- tiene un claro antecedente en el policial cinematográfico La fuga, en que Daniel Benítez (interpretado por Santiago Arrieta) era el personaje fatal que llevaba a la muerte a Cora Moreno (interpretada por Tita Merello). Y un año después este juego con los roles genéricos recibe un tratamiento comédico 
ejemplar y subversivo en Vidalita (1948), que parodia al mundo épico, heterosexual y machista del criollismo cinematográfico argentino de la primera mitad del siglo, presentando a Mirtha Legrand en el papel de una mujer que se traviste de gaucho, y se revela como el más valiente de los hombres. Por otra parte, en este diálogo fluido entre literatura y cine, la novela es llevada a la pantalla grande el mismo año de su publicación ( $A$ sangre fría, Daniel Tinayre, 1947),

En diálogo fluido con la tradición cinematográfica, la novela se aparta con decisión del modelo hegemónico de literatura policial contemporáneo, determinado en buena medida por el trabajo crítico, teórico y literario de Borges, Bioy Casares, Manuel Peyrou y Silvina Ocampo -quienes como antólogos, traductores, autores promovieron la literatura policial de enigma. Así, al seguir las pautas de la novela negra, la novela de Saslavsky es más contemporánea a la literatura mundial que la defensa de Borges del policial inglés de la edad dorada y de su desprestigio de la vertiente hard boiled.

\section{Conclusión}

En contraste con la historiografía tradicional del género, en Argentina se desarrolló a partir de la década de 1930 una literatura policial diferente a la narración de enigma o novela-problema. Esto se debió a una importante conjunción de factores: los cambios en las agencias proveedoras de noticias, la difusión de celebridades criminales, la publicación desde 1929 del Magazine Sexton Blake y de otras colecciones del género como Misterio, y el decisivo influjo del cine. Así, como hemos mostrado, en la literatura de Arlt y de Borges, los gangsters, los muchachos duros y los asesinos fríos, sin pasión ni fervor, fueron arraigándose en tierra argentina. En esta serie heterodoxa de literatura policial podemos situar, además, algunos relatos de Víctor Guillot -«En la costa», «Una historia de muertos» (Historias sin importancia, 1920), «Un asesino» (El alma en el pozo, 1925) -, «La pierna de plomo» (1933), de Nicolás Olivari, hasta llegar a las novelas cortas de Viñas de 1953, que son, en gran medida, películas de gangsters hechas novelas (Setton 2014). No hay espacio aquí para mostrar en detalle el desarrollo de esta serie. En cambio, cabe indicar que de manera simultánea el cine argentino fue desarrollando un diálogo enriquecedor con los géneros de Hollywood. Fuera de la ley (1937), de Manuel Romero, es una de las primeras películas de gangsters argentina: la recepción del género hollywoodense en la conformación del personaje y en la sintaxis del filme es evidente. $L a$ fuga (1937), de Luis Saslavsky, es una suerte de comedia gangsteril tanguera, en la que Tita Merello (en el personaje de Cora Moreno) informa a su amante Daniel Benítez (Santiago Arrieta), mediante la selección de los tangos que canta en un programa radiofónico, qué debe hacer para no ser atrapado por la policía. Monte Criollo (1935) y Palermo (1937), ambas de Arturo S. Mom, fusionan motivos del film noir y las películas de gangsters con elementos propios de la cultura popular argentina los imaginarios del tango y del criollismo-. Así, algunos elementos son resignificados: por ejemplo, el dominio de la voz, que en la tradición cinematográfica y literaria -desde la novela gótica y el policial del siglo XIX- era identificado con el mal (específicamente como rasgo definitivo de la figura del villano), ahora es ennoblecido por la heroicidad local del cantor de tangos. Así, el cine criminal (en sus diversos subgéneros, noir, gangster film, police procedural) nutrió dos series narrativas diferentes y emparentadas, la literaria y la cinematográfica, desde la década de 1920 y al menos hasta la década de 1960. Estas tradiciones, a su vez, mantuvieron un intenso y productivo diálogo entre sí. ${ }^{14} \mathrm{La}$ novela $A$ sangre fría, como hemos intentado mostrar, puede ser vista como la obra en que esas dos tradiciones se fusionan casi por completo.

\footnotetext{
Mencionamos solamente algunos pocos ejemplos, de los muchos que se podrían ofrecer: las transposiciones de Torre Nilsson de «Emma Zunz» de Borges y «El perjurio de la nieve» de Bioy Casares; Alias Gardelito (1961), de Lautaro Murúa, sobre el relato «Toribio Torres, alias Gardelito» de Bernardo Kordon; Los venerables todos (1962), de Manuel Antín y los vínculos con la novela homónima, también de su autoría, pero también con la literatura de Julio Cortázar. Por una cuestión de espacio debemos dejar este desarrollo para otra ocasión.
} 


\section{Bibliografía}

Arlt, Roberto. El crimen casi perfecto. Buenos Aires: Clarín/Aguilar, 1994.

- Novelas. Obras, tomo I. Buenos Aires: Losada, 1997.

- Aguafuertes. Obras, tomo II, Buenos Aires, Losada, 1998.

Bajarlía, Juan Jacobo. Cuentos de crimen y misterio. Buenos Aires: Jorge Álvarez, 1964.

- Historias de crimen y misterio. Buenos Aires: Fraterna, 1990.

Barcia, Pedro Luis. «Los orígenes de la narrativa argentina: la obra de Luis V. Varela». Cuadernos del Sur, 21/22, 1988/1989, pp. 13-24.

Borges, Jorge Luis. Obras completas. Barcelona: Emecé, 1989, 3 tomos.

Braceras, Elena y Cristina Leytour. Técnicas narrativas en el relato policial. Buenos Aires: La Obra, 1993.

Caimari, Lila. Apenas un delincuente. Crimen, castigo y cultura en la Argentina, 1880-1955. Buenos Aires: Siglo XXI Editores, 2004.

- «Suceso de cinematográficos aspectos». Secuestro y espectáculo en el Buenos Aires de los treinta». La ley de los profanos. Delito, justicia y cultura en Buenos Aires (1870-1940). Comp.: Lila Caimari. Buenos Aires: FCE-UdeSA, 2007, pp. 163-196.

- Mientras la ciudad duerme. Pistoleros, policías y periodistas en Buenos Aires, 1920-1945, Buenos Aires, Siglo XXI, 2012.

Charbonnier, Georges. El escritor y su obra. Entrevistas de Georges Charbonnier con Jorge Luis Borges. México: Siglo Veintiuno editores, 1967.

Cozarinsky, Edgardo. Borges y el cine. Buenos Aires: Sur, 1974.

De Rosso, Ezequiel. Nuevos secretos. Transformaciones del relato policial en América Latina 1990-2012. Buenos Aires: Liber editores, 2012.

«El asalto», Gran Guiñol, 22, Buenos Aires, 8 de septiembre de 1922, pp. 3-7

Fèvre, Fermín. Cuentos policiales argentinos. Buenos Aires: Kapelusz, 1974.
Fontana, Patricio. Arlt va al cine. Buenos Aires: Libraria, 2010.

Giardinelli, Mempo. El Género negro: ensayos sobre literatura policial. Córdoba: Op Oloop, 1996.

Gil Mariño, Cecilia. «El cine del puerto y del arrabal. Modernidad y tradición en la construcción de imágenes de lo nacional en los años treinta», Imagofagia, 5, 2012.

Gorelik, Adrián. La grilla y el parque. Espacio público y cultura urbana en Buenos Aires, 1887-1936. Buenos Aires: Universidad Nacional de Quilmes, 1998.

Juárez, Laura. ««Un argentino entre los gangsters»: El policial de Roberto Arlt en el contexto de los años treinta», Iberoamericana, XI, 43, 2011, pp. 111-128.

Lagmanovich, David. «Paul Groussac, ensayista del 80». Revista Interamericana de Bibliografía-Inter-American Review of Bibliography, vol. XXXII, 2, 1982, pp. 28-46.

- «Perfil de la narrativa policial rioplatense», Semiosis, nueva época, 2(7), 2002, pp. 46-57.

- La narrativa policial argentina. Köln: Universität zu Köln, 2007.

Lafforgue, Jorge y Rivera, Jorge B. Asesinos de Papel. Buenos Aires: Calicanto, 1977.

- El cuento policial. Antología. Buenos Aires: Centro Editor de América Latina, 1987.

- Asesinos de papel. Ensayos sobre narrativa policial. Buenos Aires: Colihue, 1996.

Lemo, Matías. «Problematización de las apariencias y discursividad de la verdad en las novelas La buella del crimen (1877) y Clemencia (1877), de Raúl Waleis». Tropelias: Revista de teoría de la literatura y literatura comparada, 31, 2019, pp. 321-340.

Mattalia, Sonia. La ley y el crimen. Usos del relato policial en la narrativa argentina (1880-2000). Madrid/Frankfurt am Main: Iberoamericana/Vervuert, 2008.

Pérez, María Laura. «Víctor Guillot: una aproximación temprana al policial negro», PhiN. Philologie im Netr, 73, 2015, pp. 101-118, http://web.fu-berlin.de/ phin/phin73/p73t5.htm.

Piglia, Ricardo. «Prólogo». Las fieras. Buenos Aires: Clarín / Aguilar, 1993.

- Crítica y ficción. Buenos Aires: Seix Barral, 2000. 
Ponce, Néstor. «Una poética pedagógica: Raúl Waleis, fundador de la novela policial en castellano». Literatura policial en Argentina. Waleis, Borges, Saer. Néstor Ponce, Sergio Pastormerlo, Dardo F. Scavino. La Plata: Universidad Nacional de La Plata, 1997, pp. 7-15.

- Diagonales del género. Estudios sobre el policial argentino. Paris: Éditions du temps, 2001.

— «Raúl Waleis». Latin American Mystery Writers: An A-to-Z Guide. Ed. Darrell B. Lockhart. Westport/ London: Greenwood Publishing Group, 2004, pp. 197-202.

Saítta, Sylvia. «Vientos de conspiración en «Los siete locos». «Los lanzallamas» de Roberto Arlt», Fragmentos, 2007, 32, pp. 39-50.

Saslavsky, Luis. A sangre fría. Buenos Aires: Shapire, 1947.

Sebreli, Juan José. «Dashiell Hammett o la ambigüedad». Escritos sobre escritos, ciudades bajo ciudades: 1950-1997. Buenos Aires: Sudamericana, 997, pp. 223-233.

Setton, Román. Los orígenes de la narrativa policial en la Argentina: recepción y transformación de modelos genéricos alemanes, franceses e ingleses. Madrid / Frankfurt am Main: Iberoamericana / Vervuert, 2012.

- «Las primeras películas criminales de Manuel Romero y sus vínculos con las representaciones precedentes del crimen en el cine argentino». Secuencias, 45, 2017, pp. 37-56, https://doi.org/10.15366/secuencias2017.45.002.
- «Las biografías criminales de David Viñas». Estudios filológicos, 53, 2014, pp. 161-170, http://dx.doi. org/10.4067/S0071-17132014000100010.

Tassara, Mabel, «El policial. La escritura y los estilos». Cine argentino. La otra historia. Comp. Sergio Wolf. Buenos Aires, Editorial Letra Buena S. A., 1992, pp. 147-67.

Tranchini, Elina Mercedes. «El cine argentino y la construcción de un imaginario criollista». El cine argentino y su aporte a la identidad nacional. César Maranghello, Elina Mercedes Tranchini y Emilio Daniel Díaz. Buenos Aires: Comisión de Cultura del Honorable Senado de la Nación / Federación Argentina de Industria Gráfica y Afines, 1999, pp. 101-174.

Vilariño, Andrea. «La revista Sherlock Holmes y la configuración del lector de policial». Orbis Tertius, 24 (29), e106, 2019, https://doi. org/10.24215/18517811e106.

Walsh, Rodolfo. Diez, cuentos policiales argentinos. Buenos Aires: Hachette, 1953.

Warshow, Robert. «The Gangster as Tragic Hero»y «Movie Chronicle: The Westernen. The Immediate Experience. Movies, Comics, Theatre, and Other Aspects of Popular Culture. New York: Anchor Books, 1964, pp. 83-88 y 89-106.

Yates, Donald Alfred. The Argentine Detective Story. Ann Arbor: University of Michigan, 1960. 